Journal of Mathematics and Statistics 5 (4): 267-269, 2009

ISSN 1549-3644

(C) 2009 Science Publications

\title{
Evolution of Spatial Correlation of Mean Diameter: A Case Study of Trees in Natural Dipterocarp Forest
}

\author{
${ }^{1}$ Rafida M. Elobaid, ${ }^{1}$ Mahendran Shitan, ${ }^{1}$ Noor Akma Ibrahim, \\ ${ }^{2}$ Awang N.A. Ghani and ${ }^{1}$ Isa Daud \\ ${ }^{1}$ Laboratory of Applied and Computational Statistics, Institute for Mathematical Research, \\ University Putra Malaysia, 43400 Serdang, Selangor, Malaysia \\ ${ }^{2}$ Faculty of Forestry, University Putra Malaysia, 43400 Serdang, Selangor, Malaysia
}

\begin{abstract}
Problem statement: Spatial modeling has many applications in various fields like agriculture, meteorology, forestry and it takes into consideration the spatial correlation structures. In the field of forestry the growth rate, in particular, the diameter of trees is usually an important parameter. The growth rate of trees in a forest is likely to be influenced by various factors like nutrients, fertility of soil, sunshine and rainfall. In this study, we investigated the spatial correlation of the mean diameter of trees in the natural Dipterocarp forest in Gunung Tebu forest reserve, Terengganu, Malaysia. Approach: The diameters were measured using the diameter tape and the unit of measurement is in centimeters $(\mathrm{cm})$. The main sampling unit was 1 ha plot of 100 by $100 \mathrm{~m}$ located approximately in the centre of each treatment block. Within the 1 ha sample plot, the quadrants $(20$ by $20 \mathrm{~m}$ ) were numbered consecutively from 1-25 and in the outer 16 quadrants; all trees having a diameter at breast height over bark $(\mathrm{dbh})$ of $15.0 \mathrm{~cm}$ or more are individually numbered, tagged and enumerated. Using the rook's and queen's neighborhood structure, we computed the Moran's spatial correlation coefficient for the mean diameter of trees in each quadrant for the years 1975 up to 1986. Results: We found that there was a negative spatial correlation among the mean diameter of trees in the 16 quadrants (cases) of the natural Dipterocarp forest in Gunung Tebu forest reserve, Terengganu at $\alpha$ level 0.10. Conclusion/Recommendations: The existence of negative spatial correlation indicated that there was competition among the trees in Dipterocarp forest as a result of tree growth over time which was affected by species, size, age and other environmental factors. Further research will concentrate on the spatial modeling of diameter of trees for the years where negative correlation was found.
\end{abstract}

Key words: Spatial correlation, Moran's correlation coefficient, queen's and rook's structure

\section{INTRODUCTION}

Spatial modeling has received much attention in recent years. The analysis of the spatial data is differentiated from the typical data analysis by the inclusion of spatial information in models and predictions. Data are often correlated in space and the spatial structure can arise from several different sources, such as measurement error, continuity effects including spatial heterogeneity and space dependent processes or mechanism ${ }^{[2]}$.

Spatial modeling takes into consideration the spatial correlation structures which can be evaluated and used to increase the accuracy of modeling and prediction efforts. A test for the spatial autocorrelation can be performed as an exploratory technique to decide whether the spatial modeling should be used. It can also be useful for testing the residuals from a standard multiple regression or trend surface models ${ }^{[4]}$.

It is also necessary to see if the value of some variable in a particular region would likely affect the neighboring regions and this is broadly known as spatial autocorrelation. The spatial autocorrelation may be computed for any lattice of regions or set of points at which the value of some variate $\mathrm{X}$ can be obtained.

Several measures of spatial autocorrelation ${ }^{[2,8]}$ were used in the literature such as the join count statistic, Moran's I coefficient ${ }^{[3]}$ and Geary c statistic ${ }^{[7]}$. In a previous research ${ }^{[5]}$ the evolution of the spatial distribution of the GDP of Asian countries using the join count statistic and Moran's coefficient was investigated.

Corresponding Author: Rafida M. Elobaid, Applied and Computational Statistics Laboratory, Institute for Mathematical Research, University Putra Malaysia, 43400 Serdang, Selangor, Malaysia 
In forestry the growth rate, in particular, the diameter of trees is usually considered as an important parameter. The growth rates of trees in a forest are likely to be influenced by various factors such as nutrients, fertility of soil, sunshine and rainfall. If the spatial correlation exists amongst trees which are contiguous or close together; the growth rate will be affected depending on the correlation structure. If there is positive spatial autocorrelation amongst the mean diameter of trees this would indicates that they are more or less alike but on the other hand a negative spatial autocorrelation would indicate that they are unlike ${ }^{[1]}$.

This study investigates the evolution of the spatial correlation of the mean diameter of trees in natural Dipterocarp forest in Gunung Tebu Forest Reserve, Terengganu in 1975-1986.

\section{MATERIALS AND METHODS}

In this study, the data set consists of the mean diameter of trees which were measured using a diameter tape and the unit of measurement is in centimeters $(\mathrm{cm})$. The main sampling unit is 1 ha plot of 100 by $100 \mathrm{~m}$ located approximately in the centre of each treatment block. Within the 1 ha sample plot, the quadrants $(20$ by $20 \mathrm{~m})$ are numbered consecutively from 1-25 (Fig. 1). In the outer 16 quadrants, all trees having a diameter at breast height over bark (dbh) of $15.0 \mathrm{~cm}$ or more, were individually numbered, tagged and enumerated (Fig. 2).

In the analysis of the spatial autocorrelation the application of contiguity measure is required. Contiguity has a rather broad definition depending on the research question; however, most analyses in spatial

\begin{tabular}{|c|c|c|c|c|}
\hline 1 & 10 & 11 & 20 & 21 \\
\hline 2 & 9 & 12 & 19 & 22 \\
\hline 3 & 8 & 13 & 18 & 23 \\
\hline 4 & 7 & 14 & 17 & 24 \\
\hline 5 & 6 & 15 & 16 & 25 \\
\hline
\end{tabular}

Fig. 1: Quadrants (20 by $20 \mathrm{~m}$ ) numbered consecutively from 1-25 within 1 ha plot

\begin{tabular}{|l|l|l|l|l|}
\hline 1 & 7 & 8 & 11 & 12 \\
\hline 2 & & & & 13 \\
\hline 3 & & & & 14 \\
\hline 4 & & & & 15 \\
\hline 5 & 6 & 9 & 10 & 16 \\
\hline
\end{tabular}

Fig. 2: Sixteen outer quadrants within 1 ha plot of 100 by $100 \mathrm{~m}$ autocorrelation adhere to a common definition of neighborhood relations such as rook's case, bishop's case or queen's (king's) case (Fig. 3).

Rook's case contiguity considers neighborhood of four locations adjacent to each cell. Meanwhile, bishop only considers the diagonal of the relationship and queen's or king's case considers a neighborhood of eight cells. In each quadrant of the grid the mean diameter of trees has been measured and spatially analyzed using the rook's and queen's neighborhood structure for the years 1975 up to 1986.

To measure the autocorrelation, the Moran's I correlation coefficient (Moran, 1950) was employed. This measure was used to evaluate the spatial pattern and examine the existence of the spatial autocorrelation among the mean diameter of trees in the different quadrants. Moran's I is one of the oldest indicators of the spatial autocorrelation, which has been used in many studies ${ }^{[6]}$. To examine the assumption of independency, the Moran's I formula used is given by:

$$
I=\frac{N \sum_{i} \sum_{j} W_{i j}\left(X_{i}-\bar{X}\right)\left(X_{j}-\bar{X}\right)}{\left(\sum_{i} \sum_{j} W_{i j}\right) \sum_{i}\left(X_{i}-\bar{X}\right)^{2}}
$$

Where:

$\mathrm{N}=$ The number of cases

$\mathrm{X}_{\mathrm{i}} \quad=$ The variable at location

$\mathrm{i}, \mathrm{X}_{\mathrm{j}} \quad=$ The variable at location $\mathrm{j}$

$\overline{\mathrm{X}} \quad=$ The mean

$\mathrm{W}_{\mathrm{ij}} \quad=\mathrm{A}$ weight applied between locations $\mathrm{i}$ and $\mathrm{j}$

$\mathrm{W}=\left\{\mathrm{W}_{\mathrm{ij}}\right\}=\mathrm{A}$ contiguity matrix and the weight assigned in this study are 1 if zone $i$ is adjacent to zone $j$ and zero if other wise

Like the correlation coefficient, the values of Moran's I range from 1, which indicates a strong positive spatial autocorrelation, to 0 which equals a random pattern and to -1 which indicates strong negative spatial autocorrelation. The Moran's I correlation coefficient was used in this study to test the following hypotheses:

$\mathrm{H}_{0}$ : No spatial autocorrelation among the mean diameter of trees in the different quadrant

$\mathrm{H}_{1}$ : Spatial autocorrelation exists among mean diameter of trees in the different quadrant

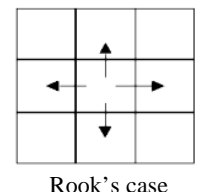

Rook's case
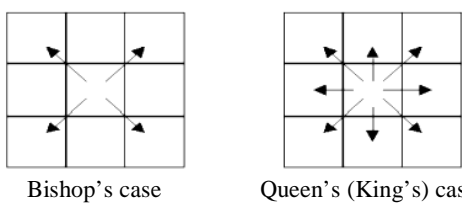

Queen's (King's) case
Fig. 3: Different definitions of contiguity 
Table 1: The $\mathrm{p}$ value using rook's and queen's neighborhood structures

\begin{tabular}{lllll}
\hline Year & $\begin{array}{l}\text { Rook's } \\
\text { corr. coef. }\end{array}$ & $\begin{array}{l}\text { Rook's } \\
\text { p-value }\end{array}$ & $\begin{array}{l}\text { Queen's } \\
\text { corr. coef. }\end{array}$ & $\begin{array}{l}\text { Queen's } \\
\text { p-value }\end{array}$ \\
\hline 1975 & -0.495 & 0.074 & -0.457 & 0.062 \\
1976 & -0.446 & 0.115 & -0.440 & 0.074 \\
1977 & -0.430 & 0.131 & -0.421 & 0.091 \\
1978 & -0.429 & 0.133 & -0.414 & 0.097 \\
1979 & -0.463 & 0.099 & -0.456 & 0.063 \\
1981 & -0.462 & 0.098 & -0.455 & 0.062 \\
1984 & -0.556 & 0.041 & -0.484 & 0.045 \\
1986 & -0.538 & 0.048 & -0.477 & 0.048 \\
\hline
\end{tabular}

Moran's I spatial correlation coefficient was calculated for the mean diameter of trees in the natural Dipterocarp forest in Gunung Tebu Forest Reserve, Terengganu in 16 quadrants (cases) for 8 years starting from 1975-1986. Both rook's and queen's structures were used.

\section{RESULTS}

Table 1 shows the results of rook's and queen's methods. Table 1 reports the correlation coefficient and p-value for each method during the years 1975-1986. Both methods produced approximately the same correlation coefficient values. However, the queen's case is more informative since it takes into consideration more neighboring regions. Table 1 also shows that over time the correlation coefficient tends to decrease.

Using the queen's structure the spatial correlation was significant for all the years at $\alpha$ level 0.10 . However, for the years 1984 and 1986 the spatial correlation is significant at $\alpha$ level equal 0.05 using both rook and queen structures (Table 1).

\section{DISCUSSION}

In this study the spatial autocorrelation between different quadrants was examined by conducting the Moran's I test statistics to the data. For this purpose, the Moran's I correlation coefficient was calculated for the mean diameter of trees in natural Dipterocarp forest in Gunung Tebu Forest Reserve, Terengganu, Malaysia, using data during 1975-1986. The study used the rook and queen structures to define the neighbors (any area with adjoining coastline is defined as an adjacent neighbor).

A contiguity matrix $\mathrm{W}_{\mathrm{ij}}$ is defined a priori by setting $\mathrm{W}_{\mathrm{ij}}=1$, if the area $\mathrm{i}$ is adjacent to area $\mathrm{j}$ and zero, otherwise. The Moran's I correlation coefficient was calculated to test the null hypothesis of no spatial autocorrelation. The p-values using the rook's case indicate that the coefficient is significant at 0.1 level during the years 1975 and 1979-1986. Meanwhile, the queen's case, which consider more neighbors, show significant results at 0.1 and 0.05 level for all the years.
This suggests that there is a spatial autocorrelation exist among the different quadrants.

The results also show that this spatial autocorrelation among the mean diameters of the trees is negative. This provides statistical evidence that there may be a competition among the trees as a result of tree growth over time which is affected by species, size, age and other environmental factors.

\section{CONCLUSION}

In this review study we have examined the spatial autocorrelation of the mean diameter of trees in natural Dipterocarp forest. Using two different neighboring structures; Moran's I correlation coefficient suggests that there is a negative spatial correlation exist among the neighboring quadrants in the natural Dipterocarp forest, in Gunung Tebu Forest Reserve, Terengganu, Malaysia. Such results can be evaluated and used to increase the accuracy of the future prediction efforts. The study also suggests that the spatial structure is one of the important factors that influence and explain the behavior of the natural forest growth. For further research spatial modeling of diameter of trees can be under taken.

\section{REFERENCES}

1. Cliff, A.D. and J.K. Ord, 1981. Spatial Autocorrelation. Pion, London, ISBN: 0850860369, pp: 178.

2. Haining, R., 1990. Spatial Data Analysis in the Social and Environmental Science. Cambridge University Press, Cambridge. ISBN: 0521448662, pp: 410.

3. Moran, P.A.P., 1950. Notes on continuous stochastic phenomena. Biometrika, 37: 17-23. http://www.ncbi.nlm.nih.gov/pubmed/15420245

4. Ripley, B.D., 1981. Spatial Statistics. Wiley, New York. ISBN: 0417083674, pp: 260.

5. Mohammad, R. and M. Shitan, 2002. Evolution of the spatial distribution of GDP of Asian countries. Proceedings of the Asia Pacific Economics and Business Conference, University Putra Malaysia Press, Kuching, Sarawak. ISBN: 9832373-65-4, pp: 700-703. 2-4 October.

6. Upton, G.J. and B. Fingleton, 1989. Spatial Data Analysis by Example, Point Pattern and Quantitative Data. Vol. 2. Wiley, New York. ISBN: 047192086X, pp: 416.

7. Geary, R.C., 1954. The contiguity ratio and statistical mapping. Incorporat. Stat., 5: 115-145.

8. Goodchild, M.F., 1986. Spatial Autocorrelation (Concepts and Techniques in Modern Geography). GeoBook, UK., ISBN: 0860942236, pp: 56. 